\title{
e-Payment System Drive Thailand to Be a Cashless Society
}

\author{
Somkid Yakean* \\ School of Business and Communication Arts, University of Phayao, Phayao, Thailand.
}

\begin{abstract}
Thailand has to go for a cashless society because to change ourselves or our-system, it is nature. This article explains how the e-Payment system drives Thailand to be a cashless society. e-Payment system plays a crucial role in driving Thailand to be a cashless society. This system supports the financial transactions for public and private sectors to be more efficient, transparent, safe, and low-cost. It also supports the growth of SMEs, e-commerce, and large businesses. All e-payment system transactions are executed electronically rather than using cash and cheque. The e-Payment system consists of a credit card, ATM card, direct debit, Internet/mobile banking, e-Wallet, PromptPay, and QR code. The PromptPay and QR code are the mainly e-Payment system that drives Thailand to be a cashless society. Finally, Thailand will be a cashless society in which they improve infrastructure and educate people on the benefits and how are merit of the e-Payment system.
\end{abstract}

Keywords: Cashless, e-Payment, PromptPay, QR Code, Payment System.

\section{INTRODUCTION}

Bank of Thailand (BOT) (2020) defined the payment system is the process of delivering or transferring money to settle financial obligations. The payment system plays a critical role in supporting the public sector, private sectors, and financial institutions to execute financial transactions more conveniently, quickly, safely, and efficiently. In addition, this system supports the functioning of economic activities more accuracy and helps the user to do financial transactions more efficiently and safely. In 2017, the Bank of Thailand (2017) set up "the Payment System Roadmap for Thailand" and "National e-Payment System Master Plan" which aim to drive Thailand to be a cashless society and to encourage the use of e-payment, such as PromptPay, Electronic Data Capture (EDC) and Quick Respond Code (QR Code). Moreover, the development of financial technology is putting the paperbased payment system under pressure and force people to accept the e-payment system. Covid-19 is not only a worthwhile situation for people, but it creates the opportunity for businesses and people to adopt e-payment in their life.

As mention above, the government and the Bank of Thailand want Thailand to be a cashless society, so this article aims to explain how Thailand can be a cashless society.

\section{OBJECTIVES}

This article aims to provide information on how the epayment system drives Thailand to be a cashless society.

\section{BACKGROUND OF PAYMENT SYSTEM IN THAI- LAND}

The Payment system in Thailand consists of a paper-based system and an electronic payment system. The former is a

\footnotetext{
*Address correspondence to this author at School of Business and Communication Arts, University of Phayao, Phayao, Thailand;

Tel: (66) 088245 0338; E-mail: audyken@yahoo.com.com
}

traditional system, while the latter is an advanced technology system. The difference between the paper-based system and the e-payment system is that the paper-based system is treated as a former of goods/commodities, whereas the e-payment system is a form of services. The paper-based system includes cash and cheque that involves a buyer to seller transfer of cash information. The electronic payment system is known as the e-Payment system. This payment system comprises a credit card, Automated Teller Machine (ATM) cards, direct debit, Internet/mobile banking, e-Wallet, PromptPay, and Quick Response (QR code). The credit card is issued by banks or non-banks, allowing the cardholders to make purchases or payments on credit and repay later. Moreover, credit cards can be integrated into other epayment systems such as e-wallet and public transportation payment systems. The ATM card is allowed the ATMcardholders to withdraw cash, fund transfer, and check the balance at the ATM vendor machines. This payment system is also able to support the banks and non-financial institutions to reduce their operational cost, e.g., logistics, cash holding costs, and labor-saving. The ATM cardholders get the benefit from this system which they are able to execute financial transactions through ATM vendor machines anywhere. A Direct debit card is a payment system for goods and services. It is the most popular payment type for utility bills since this system is able to directly deduct the money from theirs's client account. Internet/mobile banking is an ePayment system that allows users to execute financial transactions through a mobile device such as a computer, a smartphone, a tablet, or a smartwatch. This payment system is able to assist users to execute financial transactions more convenient and quick for everyday spending, at a lower fee. This payment system also allows users to make financial transactions anywhere that have an internet connection, so the users have more time for other endeavors. Moreover, this payment system is able to assist the financial institutions to increase revenue by expanding their product with offerings 
via Internet/mobile banking beyond current transactional products.

e-Wallet is also known as an e-Money, this payment system needs an e-Wallet ID for identification clients. The e-Wallet ID refers to the 15-digit electronic that clients receive from bank/non-bank providers, once completed the Know Your Client (KYC) process. e-Wallet is an e-Payment that users are able to make online financial transactions through a computer, a smartphone, or a tablet. This payment system helps the clients to make payments for anything more convenient and quickly at a lower fee. Moreover, a mobile wallet is a payment system that users are able to execute financial transactions with a smartphone, a tablet, or a smartwatch instead of using a plastic card. In addition, e-wallet develop into much more than just digital cards, for instance, TrueMoney wallet, 7-Eleven App wallet, and royalty cards. TrueMoney Wallet is a payment system that allows clients to pay for anything by top up with cash or auto-topped up when connected to a bank account that is able to assist Thai migrant workers who do not have a bank account to transfer money from Myanmar and Cambodia to their families, without bank account of the receiver. The 7-Eleven App Wallet provides services to clients that is able to pay for anything at 7 -eleven stores over 10,000 stores in Thailand. This payment system is able to support them to create promotional campaigns and to reward a client's loyalty. Moreover, Starbucks, S\&P, Amazon, and the CRG (Central Restaurants Group) cards provide the services to the cardholder to make cashless payments and collect points at the same time, which they can use the point to redeem rewards as theirs campaigns.

On June 15th, 2016, the Bank of Thailand had launched the PromptPay, which the purpose to serve the government welfare disbursements. This payment system is a real-time fund transafer system. Afterward, this payment system provides services for funds transfer between individuals and juristic persons and other overlay services. In 2017, this payment applied a National ID number or mobile number as a proxy of bank account number. This system helps the users to make fund transfers faster and conveniently. This payment system is centralized that can execute financial transactions from all channels including ATM, bank counters as well as Internet/mobile banking transactions. Transferring fees via Promptpay is a low charge of fees with a range from THB 0 to 10 which the services providers might charge as much as THB 35 for funds transfer between clearing districts, even to an account at the same banks. This payment system is offered similar to fast payment services available in many countries, e.g., Paym of United Kingdom, PayNow of Singapore, and OSKO of Australia. The PromptPay is provided the benefits to businesses which is able to saving cost, reduce paperwork, and cash processing as well as the opportunity to sell their product online and instantly receive payment. Moreover, this payment system will also improve the government welfare disbursements to be more transparent and accurate because it is electronically transferred with receipt's national ID number.

The standard QR Code is a standard for payments and funds transfer, which allows business to accept payments directly into their bank accounts without having to invest in the electronic data capture (EDC). This payment system provides the benefits to small businesses and the public transportation services providers to receive money at the point of service/sales which users no need to scan different QR codes when executes payments for services/goods, while businesses only have to display one QR code for receiving payments, but this payment system only needs a smartphone or a tablet and a Promptpay account to make payments. The Bank of Thailand had developed the QR Code system that users are able to pay from any debit card, credit card, bank saving accounts, e-Wallets from domestic or foreign non-bank service providers. The non-banks such as TrueMoney, m-Pay, AirPay also are promoted their services to attract more eWallet users. Moreover, the government had developed the e-donation QR code that allows users to donate money for charitable organizations such as the temple and foundation by scanning QR code where information will be directly sent to the revenue department for the tax rebates. Users will receive an electronic tax certificate that can use for tax rebate filling.

\section{LAW SUPPORT OF CASHLESS SOCIETY}

In 2017, the BOT and the Ministry of Finance enacted the Payment Systems Act 2017 (B.E. 2560) for moving Thailand into a cashless society. The ACT reduces the redundancy of existing laws and regulations and provide an ecosystem in support of innovative services and consumer protection. Concerning cyber risk, the BOT conducted an assessment on cybersecurity readiness on Thai commercial banks, specialized financial institutions (SFIs), and payment service providers, following the international standards, to identify further improvements required in the cybersecurity management. Moreover, the BOT established the Thailand Banking Sector Computer Emergency Response Team to manage cybersecurity. These have made a strong foundation for efficient and secured Thai payment systems, which will be one of the keys to the sustainable development of the Thai economy and driving Thailand to a cashless society.

\section{DATA OF PAYMENT SYSTEM IN THAILAND}

Both government and private sectors have been encouraging people to use e-Payment system such as credit/debit cards, internet/mobile banking, PromptPay, QR code, and e-Wallet as the advantages of the move towards a cashless society are enormous. As a results of the promoted e-payment system, the value of payment transactions via e-Payment increases every year, as shown in Fig. (1).

As shown in Fig. (2), most people are willing to use ePayment for financial transactions. The Internet/mobile banking, PromptPay, e-Wallet are rapidly popularizing among Thai people to use for their financial transactions. Most people use the Internet/mobile banking for an ecommerce business because this payment system is convenient and lower fees to make payments. They can execute financial transactions anywhere with having an internet connection. Most people rely on PromptPay, because they registered numbers adopted PromptPay for government welfare disbursement, government transfers, and tax refund. Moreover, most people use PromptPay for daily low-value funds transfers and payments due to the convenience of funds transfer, where a fee of financial transaction is exempted for 


\section{Billions of THB}

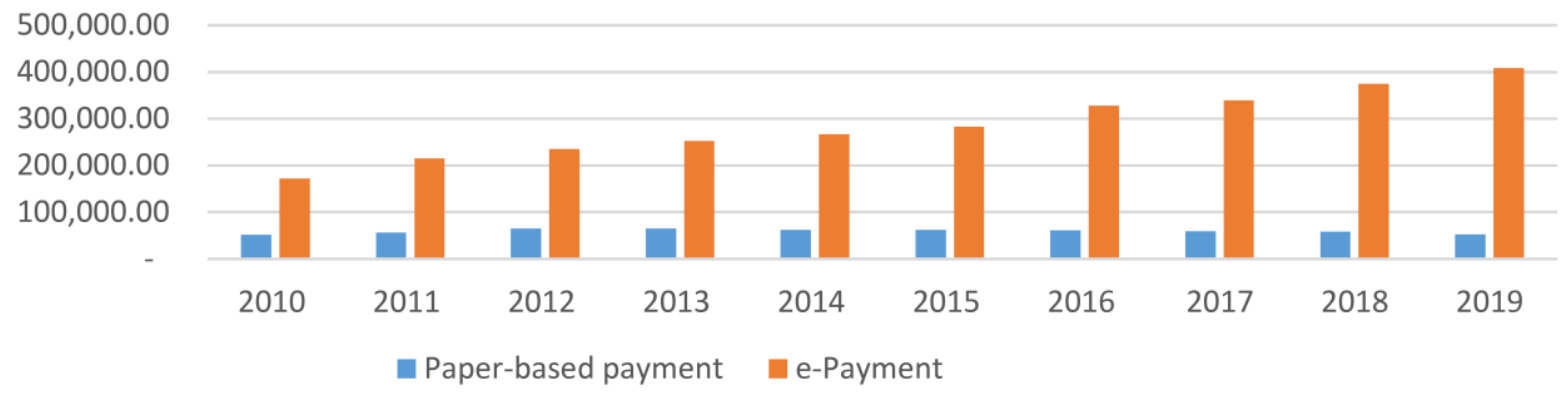

Fig. (1). Value of Payment Transactions.

Source: Bank of Thailand.

Thousand Transactions

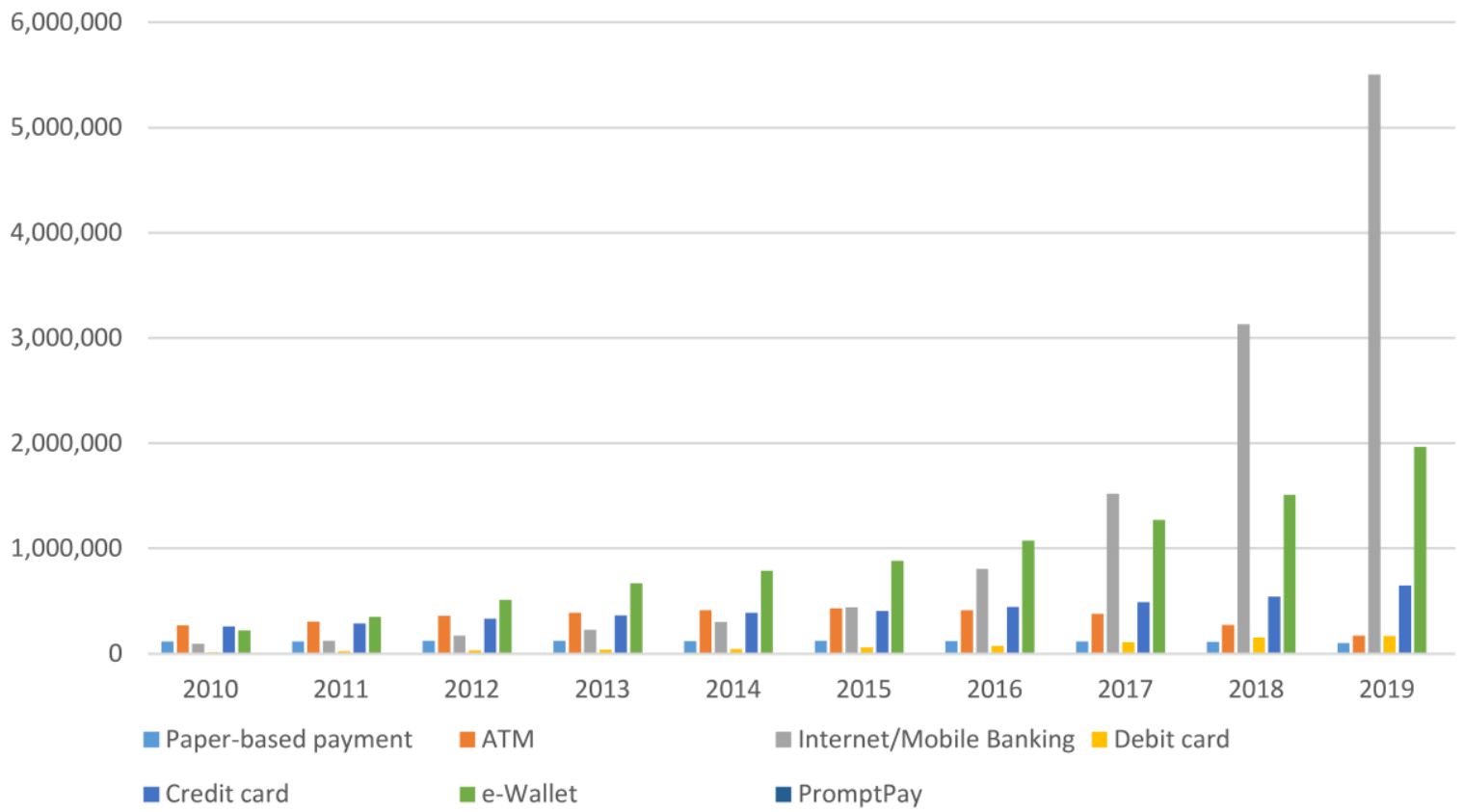

Fig. (2). Volume of Payment Transactions.

Source: Bank of Thailand.

the fund transfer of THB 5,000 or less, and the number of transfers allowed per day is unlimited.

Figs. (2 and 3) show the volume and value of e-Payment in Thailand that increase every year. Most people rely on the ePayment system and prefer to make financial transactions on this system. A result of using e-payment indicate that Thailand moves toward being a cashless society.

\section{REVIEW OF LITERATURE}

Lamsan, A., Pinthong, J., Shimnon, A., and Trakiatkul P. (2018) concluded that e-payment system includes PromptPay, mobile/internet banking play a significant role in driving toward a Thailand to be cashless society.

Gohwong, H. (2017) concluded that PromptPay was the most popular e-payment system, follow by, Internet/Mobile banking, credit cards, and Bathnet respectively.
Goel, R., Sahai S., Vinaik, A., \& Gang, V. (2019) concluded that the working profession and business class people use digital payment methods more since they preferred to get the cashback from the payment system. The government needs to develop infrastructure since people are not trusting of digital payment system and lack of confidence while using of digital payment system.

Bech, M., Forugui, U., Ongaard, F., \& Picillo, C. (2018) concluded that cash had been the preferred payment system in the most developed economies because of the start of the financial crisis.

Ramya, N., Sivasakthi, D., \& Nandhini, M. (2017) concluded that the cashless make the financial transaction more transparent, scalability, and accountable. This merit of cashless will compel the business and people to accept the epayment. 


\section{Billion THB}

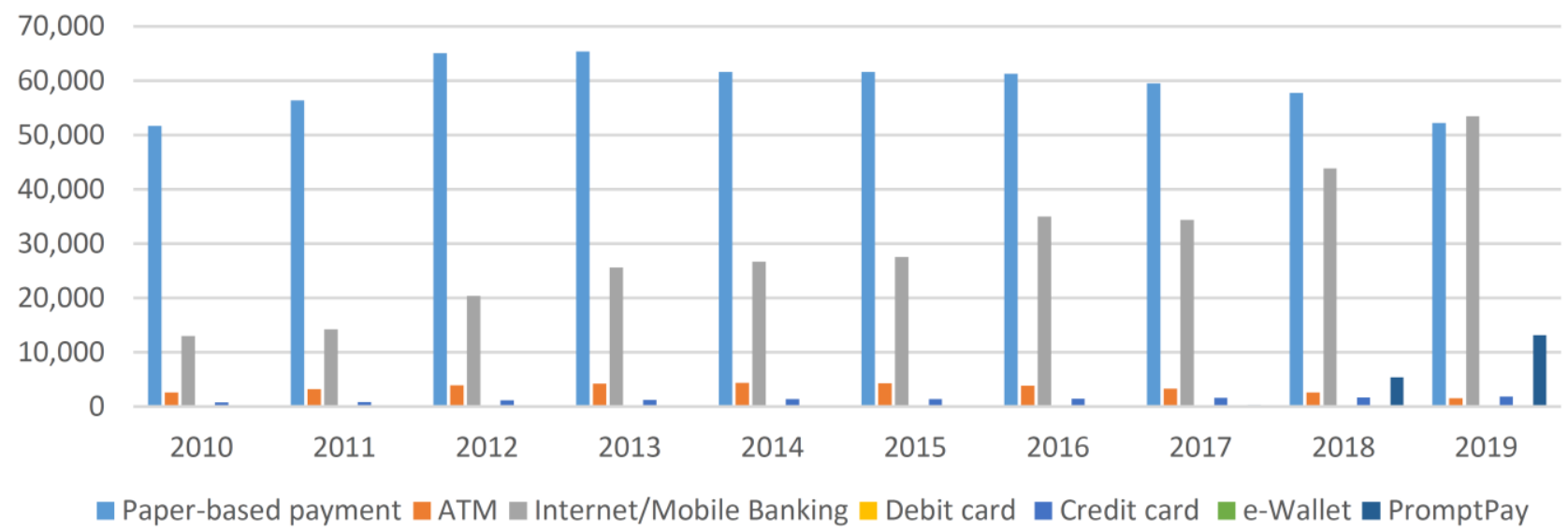

Fig. (3). Value of Payment Transactions.

Source: Bank of Thailand.

Sumanjeet, S. (2010) summarized that the growth of ecommerce needs the e-payment to support their business. Credit cards, internet banking, and mobile banking are the most e-payment system to support e-commerce. Since this system are security acceptability, convenience, cost anonymity contra, and trackability.

Boonsang P. (2017) concluded that the users in Thailand would accept the e-payment system and would intend to use e-payment.

Koponen, A. (2006) concluded that e-commerce had changed the financial transaction. The business needs the epayment to support their business in online business. Moreover, e-commerce has changed the banking activities publishing including electronic distribution, sale portal covering sales, market, production management and distribution the personal privacy security and application technology is a main concern of users.

Visa Cards (2017) concluded that medium and large firms in Bangkok prefer to use e-Payment than smaller firms. The small firms in Bangkok still rely on cash because they are limited to apply the e-Payment system. Moreover, small firms prefer to accept money in business because it saves transactions cost for them than using e-payment. The development of cashless in China and Indian can enable the creation of a financial database of SMEs and consumers. This payment system is able to support the financial institutions to do business more efficiently. This e-payment can support the growth of SMEs and enhance personal financial planning. Finally, this payment system is able to support the government to design appropriate and effective policies by using ePayment data.

\section{FACTOR ACCELERATING THAILAND MOVING TO A CASHLESS SOCIETY}

The following are the factors accelerating Thailand to be a cashless society.

1. A growing number of smartphone users will encourage the growth of e-payment users.
2. The development of broadband and mobile telecommunications networks is the key to moving Thailand to a cashless society.

3. Most people rely on the e-payment system.

4. Fees for financial transactions through e-payment are low.

5. The government established the National e-Payment system to support the cashless society.

6 . The collaboration between the public sector and the private sector will help to drive Thailand to be a cashless society.

7. Thai people are open-minded about the e-Payment system.

8. Making financial transactions via e-Payment is very easy, convenient, and safer.

9. Both the public sector and private sector continue to develop the e-Payment to support a cashless society.

10. Thailand have many types of e-Payment system that is able to match the user needs and knowledge. For example, they have Internet banking, PromptPay, QR code, and eWallet that match the users and providers.

11. The government had amended the payment system law for supporting a cashless society.

12. Without the development of PromptPay, Thailand cannot be a cashless society, since PromptPay can serve all parties.

13. The Covid19 Pandemic is helped to growth of e-Payment since this payment is able to reduce the spread of Covid 19.

Moreover, the development and implementation of a safe and efficient national payment system is to reduce poverty and boost prosperity. Secure affordable and accessible payment systems and services promote development, support financial stability, and help expand financial inclusion.

\section{CONCLUSION}

Thailand moving to cashless is an alternative to improve overall financial transactions for society. It also brings better transparency, scalability, and accountability. Promoting e- 
Payment and reducing cash usage in daily life can be achieved by educating the public and private sectors on how e-Payment works and its benefits. This drive Thailand to a cashless society. The cashless will benefits businesses, government, and people by making transactions more convenient and less costly. The launch of PromptPay, internet/mobile banking, QR code, and e-Wallet is a key system to drive Thailand to become a cashless society. Both public and private sectors play a role in making-payment system more efficient and more accessible to low-income peoples, that it is one factor to drive to be a cashless society. Finally, without developed the PromptPay, Thailand cannot be a cashless society because this e-payment system is easy to use and efficient payment system.

\section{SUGGESTION}

Thailand cannot be a cashless society if they do not develop the infrastructure and number of users. Both the public and private sectors should develop e-payment tools that can use so easy, convenient, and suitable for all users. The private sector should develop an e-payment system that is tailored to the need of use and easy to understand and use. Finally, both public and private sectors should educate the benefits of cashless to people.

\section{CONFLICT OF INTEREST STATEMENT}

The authors declare that they have no conflict of interest.

\section{REFERENCES}

Bank of Thailand. (2016). PromptPay Ready to Use. Retrieved May 1, 2020, from

https://www.bot.or.th/Thai/PaymentSystems/PSServices/PromptPa y/Pages/default.aspx

Bank of Thailand. (2017). Payment System Roadmap No.4 (2019-2021). Retrieved May 1, 2020, from https://www.bot.or.th/English/PaymentSystems/PolicyPS/Documen ts/PaymentRoadmap_2021.pdf

Bank of Thailand. (2018). Payment Systems Report 2017. Retrieved May 1. 2020 , from
https://www.bot.or.th/English/PaymentSystems/Publication/PS_An nually_Report/Documents/Payment_2017_E.pdf.

Bank of Thailand. (2018). Payment System: Standardized QR Code in Thailand. May 1, 2020, from https://www.bot.or.th/Thai/AboutBOT/Activities/event/Documents /ADBI_bancha.pdf

Bank of Thailand. (2019). Oversight of Payment System. Retrieved May 1, 2020, from

https://www.bot.or.th/English/PaymentSystems/OversightOfPayme ntSystems/Pages/default.aspx

Bank of Thailand. (2020). Payment Transactions. Retrieved May 1, 2020, from

https://www.bot.or.th/English/Statistics/PaymentSystems/Pages/Sta tPaymentTransactions.aspx

Bank of Thailand. (2020). Statics of Payment System. Retrieved May 1. 2020, from

https://www.bot.or.th/Thai/PaymentSystems/PSServices/PromptPa y/Pages/default.aspx

Bech, M., Forugui, U., Ongaard, F., \& Picillo, C. (2018). Payments are aChangin' but Cash still Rules. BIS Quarterly Review, March 2018. 67-79.

Goel, R., Sahai S., Vinaik, A., \& Gang, V. (2019). Moving From Cash to Cashless Economy: A Study of Consumer Perception Toward Digital Transactions. International Journal of Recent Technology and Engineering (IJRTE), Vol 8(1) May 2019. 1220-1226.

Gohwong, H. (2017). The State of the Art and Trend of Cashless Society in Thailand. Asian Political Science Review, Vol. 1(2). 65-72.

Koponen, A. (2006). E-Commerce, Electronic Payments. Retrieved May 1, 2020, from https://www.scribd.com/document/455215669/ECommerce-Electronic-Payments-pdf

Lamsan, A., Pinthong, J., Shimnon, A., and Trakiatkul P. (2018). The Journey to Less-Cash Society: Thailand's Payment Sysem at a Crossroads. Puey Ungphakorn Institute for Economic Research Discussion Paper No. 101. Bangkok.

Pimnipa, B. (2017). Why s is Essential to Merchant as Thailand becomes a Cashless Society. Retrieved May 1, 2020, from https://www.scb.co.th/en/personal-banking/stories/are-you-readywith-virtual-money.html

Ramya, N., Sivasakthi, D., \& Nandhini, M. (2017). Cashless Transaction: Modes, Advantages and Disadvantages. International Journal of Applied Research, 3(1). 122-125.

Sumanjeet, S. (2010). Emergence of Payment System in the Age of Electronic Commerce: the State Art. Asia Pacific Journal of Finance and Banking Research Vol. 3, No. 3, 2009. 18-40.

Visa Card. (2017). Cashless Cities Technical Appendix. Retrieved May 1. 2020, from

https://usa.visa.com/dam/VCOM/global/visaeverywhere/documents/visa-cashless-cities-technical-appendix.pdf 